\title{
La capacidad de "darse cuenta": corporalidad consciente del artista escénico
}

\author{
M.H. Perla Jazmín Lopez Peñuelas \\ Universidad de Sonora. \\ Departamento de Bellas Artes \\ perla_f05@hotmail.com
}

\section{Introducción}

Spinoza dijo una vez: "nadie sabe lo que puede un cuerpo". Este filósofo dio fe de un despertar humano a su propia capacidad de vivir y soñar el cuerpo. Las prácticas escénicas se han diversificado en la aventura de explorar y jugar con lo que el cuerpo puede. Pero tanto en el ámbito académico como en el artístico, este juego siempre parte de un programa de acción o al menos una serie de reglas que determina el juego.

A menudo - en un afán por priorizar el valor estético del arte -, perdemos de vista las implicaciones que tiene jugar de una u otra manera. A través de esta reflexión busco poner el acento en la corporalidad del artista escénico, misma con la que se construye como artista y absorbe también una serie de aspectos socio-culturales. El presente trabajo surge de una continua acción investigadora desde la práctica docente, desde la experiencia escénica y desde la investigación sobre las acciones escénicas y el comportamiento del artista escénico en el proceso creativo ${ }^{1}$.

Más allá de los respectivos saberes disciplinares adquiridos en el proceso de formación y adquisición de técnicas, los artistas encarnamos una práctica y comportamiento escénico que resulta de una forma específica de acumular, mezclar, intercambiar y apropiarnos de saberes específicos. Es decir, cada uno pone sus propias reglas del juego, aunque en gran medida están predeterminadas por nuestros procesos de formación e influencias.

\section{De lo consciente, lo inconscien- te y la energía}

La tendencia del artista escénico contemporáneo es holística, pero necesariamente puede atender sólo algunos de los muchos aspectos que conforman su experiencia, que cuanto más precisos, dan lugar a una experiencia más profunda y consciente de su corporalidad. Y es a partir de esa corporalidad que ejercemos nuestra capacidad de transformar la realidad y de vivenciar una experiencia que nos distingue y también reafirma frente a otros artistas. Antes de continuar con esta reflexión, creo necesario precisar el significado de algunas nociones que solemos usar cotidianamente dentro de nuestros procesos creativos, cuyo significado es ambiguo e interpretado de diferentes maneras: consciencia, experiencia y energía. Puesto que estas nos ayudarán a ubicar el comportamiento del actor-bailarín a la luz de su experiencia, la parte consciente de esta experiencia y por último, el lugar de la energía de la que tanto se habla en la práctica y teoría del arte escénico.

Una cosa es utilizar un término convencionalmente al interior de un gru-

${ }^{1}$ Estas reflexiones se basan en gran medida en el trabajo de investigación que para obtener el grado de Maestría en Humanidades presenté en la Universidad de Sonora bajo la modalidad de tesis cuyo título es "La capacidad de darse cuenta. Corporalidad consciente del actor-bailarín en la danza-teatro de Pina Bausch y el teatro que danza de Eugenio Barba" (2016). 
po (como el de consciencia), pero este no necesariamente coincide con alguna acepción científica, sino que forma parte del vocabulario y los acuerdos internos de cada pequeña cultura teatral. A través de las siguientes consideraciones trato de ubicar nuestras acciones como artistas escénicos en un contexto más amplio y en relación con nuestro entorno sociocultural proponiendo una base común de la cual partir en nuestro entendimiento de estos conceptos.

Empezaré definiendo el terreno de la experiencia. La experiencia atañe a lo procedimental y no a lo factual. Por lo tanto, la experiencia es antes a la nominación de la cosa. El especialista en psicología y neurociencia, Jacobo Grinberg Zylberbaum, define la experiencia como un todo que incluye sentimientos, emociones, percepciones, pensamientos, sensaciones corporales, imágenes, y aun, la consciencia. Sería la experiencia todo lo que se vive tanto consciente como inconscientemente. Esta noción va más allá de la idea de la experiencia como maduración psicológica o de la adquisición de técnica, memoria y aprendizaje (1981, p. 25).

La consciencia por su parte, sería la experiencia de "darse cuenta", ello implica poder ver desde puntos de referencia más extensos, generalizados o inclusivos (p. 25). "Darse cuenta" implica unificar lo que estaba disperso e implica también una mayor capacidad para reconocer relaciones entre eventos.

El nivel de consciencia varía de acuerdo al nivel de codificación al que se tenga acceso y cada nivel implica una transformación distinta del contenido energético puro del espacio (p. 38). Si nos basamos en esta afirmación habría por un lado, niveles básicos de la experiencia de la consciencia y niveles superiores; y por el otro, en cada nivel una distinta forma de crear y transformar la energía (p. 19). Esta energía se definiría aquella potencialidad contenida en el espacio y a la que el artista accedería mediante la consciencia o el "darse cuenta" de su experiencia.

Cuando el comportamiento del artista tiende a desarrollar una mayor capacidad de "darse cuenta", se puede decir que también tiene la tendencia a buscar la equivalencia entre experiencia y conciencia. Esto no es otra cosa que haya cada vez una mayor trasformación de contenidos inconscientes a la consciencia de los mismos.

El resultante de un procesamiento consciente sería siempre la aparición de lo fundamental (p. 39). El consciente sería el resultado de un procesamiento neuronal y el inconsciente toda la información neuronal previa a al producto final, es decir, sus elementos constitutivos (p. 40). Lo anterior implica una mayor capacidad de discriminación temporal, mayores detalles, mayor precisión perceptual y mayor capacidad de detectar los mínimos cambios.

El procesamiento neuronal implica entonces un regreso a lo primitivo, un descomponer en sus elementos constitutivos, y también el hecho de trascender la estructura que se procesa y volverla relativa. Por estructura entenderíamos aquella que formamos a partir de un conjunto de relaciones y que a su vez forma parte constitutiva de otras estructuras.

Cualquier estructura (conjunto de relaciones) que se trasciende no se destruye, sino que se transforma, el sujeto puede mantenerse dentro esa estructura solo que ya no se identifica ni depende vitalmente de ella, se relativiza (p. 329). En proceso del trabajo consigo mismo, los artistas pueden trascender algunas de sus estructuras profesionales y culturales, pero ello no significa que las abandonen, sino que esta información (identificación de lenguaje, códigos o vivencias) se incluye, converge o concentra en el siguiente nivel de consciencia. A través de la autoexploración de sus propios procesos tienden a reconocer patrones de pensamiento y emociones, y 
tienden por tanto, a relativizarlos.

Para "darse cuenta" de sus estructuras de pensamiento y emociones los artistas, cada quien dentro de sus distintos sistemas de entrenamiento, exploran diferentes zonas de consciencia. Resulta útil la propuesta de John O. Stevens para clarificar las zonas de trabajo de los actores y bailarines (Ver Tabla 1). Estas zonas serían: el mundo interior, el mundo exterior y las creaciones mentales. El teatro basado en la literatura dramática y de re- presentación realista, por ejemplo, tiende a poner el acento en el mundo interno y el de las creaciones mentales. Mientras que la danza basada en el movimiento por el movimiento, pone el acento en el mundo físico interno y externo. En cambio otras formas de arte como la de los actores-bailarines o performers tienden a situarse de una forma más equilibrada en estas tres zonas de consciencia (interna, externa y mental).

Tabla 1: Elaboración propia basada en El "darse cuenta" de John O. Stevens

Zonas de consciencia

\begin{tabular}{|c|c|c|c|}
\hline $\begin{array}{l}\text { Mundo } \\
\text { interior }\end{array}$ & $\begin{array}{l}\text { Contacto sensorial } \\
\text { actual con eventos } \\
\text { internos del presente: } \\
\text { Lo que ahora siento } \\
\text { desde debajo de mi } \\
\text { piel. }\end{array}$ & $\begin{array}{l}\text { Sensaciones, } \\
\text { tensiones musculares, } \\
\text { manifestaciones } \\
\text { físicas de los } \\
\text { sentimientos y las } \\
\text { emociones. }\end{array}$ & $\begin{array}{l}\text { Comunicación } \\
\text { interior }\end{array}$ \\
\hline $\begin{array}{l}\text { Creaciones } \\
\text { mentales }\end{array}$ & $\begin{array}{l}\text { Va más allá de lo que } \\
\text { transcurre en el } \\
\text { presente: fantasia e } \\
\text { imaginación. }\end{array}$ & $\begin{array}{l}\text { Todo lo que explico, } \\
\text { imagino, pienso, } \\
\text { planifico, recuerdo o } \\
\text { anticipo. }\end{array}$ & \\
\hline $\begin{array}{l}\text { Mundo } \\
\text { exterior }\end{array}$ & $\begin{array}{l}\text { Contacto sensorial } \\
\text { actual con objetos y } \\
\text { eventos del presente: } \\
\text { Lo que en este } \\
\text { momento percibo a } \\
\text { través de mis sentidos. }\end{array}$ & $\begin{array}{l}\text { Lo que veo, palpo, } \\
\text { toco, escucho, degusto } \\
\text { y huelo. }\end{array}$ & $\begin{array}{l}\text { Comunicación } \\
\text { con otros }\end{array}$ \\
\hline
\end{tabular}

\section{El "darse cuenta" como acción} liberadora

En este constante llevar al terreno de la consciencia cada vez más aspectos de su corporalidad, los artista suelen reconocer sus propios argumentos vitales. Estos serían los que el psicólogo Jonh Stevens define como aquellos esquemas ritualizados de roles, metas, fines, imágenes y demandas que guían nuestras acciones y parcialmente determinan lo que sucederá (1998, p. 184). Estos son adquiridos a los largo de nuestra vida y de nuestros procesos formativos a veces de manera incons- 
ciente. Muchos procesos de formación proporcionan al estudiante espacio-tiempo para enfrentarse y muchas veces romper con este sistema valores y creencias primero en un aislamiento seguro, vivenciando su individualidad, y después en contacto con el mundo. De esta manera, hacernos conscientes y acceder a nuestras imágenes, fantasías y memorias, nos permite completar ciertas estructuras y acceder a otros niveles de conciencia.

Para el psicólogo John Stevens, descubrir cosas ocultas en nuestras fantasías, así como sentimientos no expresados, nos permite una liberación de energía que hemos estado empleando inconscientemente en estas cosas ocultas. Es decir, que hasta no darnos cuenta de esos sucesos inconscientes y digerirlos, la energía que contienen no está disponible. Por lo tanto, puede decirse que siempre hay una liberación de energía en el "darse cuenta" (Stevens, 1998, p. 83).

En cambio, cuando se evita la conciencia de cómo el cuerpo se expresa a través del movimiento, también se evita el sentir y hay una interrupción parcial o total del movimiento, visible en los puntos de tensión. La tensión nos indica que ese flujo está siendo interrumpido. Y sólo puede interrumpirse el flujo y generar un punto de tensión, tensando los músculos que se oponen a ese flujo (Stevens, $p$. 87). Es así como aparecen las señales de que algo quiere expresarse pero está siendo inhibido.

Es imposible no comunicar, pues todo lo que no se expresa de modo abierto busca expresarse de alguna otra manera; una sonrisa afectada, una risa nerviosa, algún punto de tensión (Stevens, 1998, p. 120). Si quiere liberarse la energía empleada en un punto tensión, algo necesita llevarse al terreno de la conciencia y así liberar la energía que se ocupa en ese punto de tensión.

Algunos directores de escena trabajan de manera constante en señalar esos puntos de tensión donde algo quiere ser expresado y está siendo reprimido, y con ello trabajan directamente sobre el "darse cuenta" de sus pensamientos y emociones, para de esta manera, incidir en el movimiento o en la configuración de la acción visible. A manera de un coordinador de terapias insisten en hacer que la persona contacte con su propia experiencia y trate de despertar el potencial en desuso.

En cambio, en otros casos, se trabaja directamente en las tensiones físicas y la liberación de canales energéticos, lo que probablemente modificará posteriormente los estados emocionales y sentimientos. Pues dado a que ambas cosas con interdependientes, la exploración de zonas de tensión, también es una exploración del espíritu.

Según Stevens, una exploración de las zonas ocultas del individuo, nos lleva a descubrir más respecto de la vida y a ser menos disociados. Esto implicaría nuevas cosas respecto a nuestras propias dificultades y también, tener más responsabilidad en el actuar, ser más directo y honesto, más efectivo. En general, nos llevaría a sentir menos frustración, pues te haces consciente de tus reservas de energía y encuentras la forma de liberarla (Stevens, 1998, p. 93).

En este proceso de autoconocimiento y liberación radica la particularidad de los directores, coreógrafos, compañeros de escena o particulares procesos creativos que atraen a los artistas escénicos por su particular forma de llevarlos a descubrir más acerca de su propia individualidad y contacto con el mundo. De allí la sensación de libertad.

\section{La capacidad de "darse cuen- ta" en los procesos formativos}

Si entendemos la frustración como la imposibilidad de satisfacer una necesidad o deseo. La energía liberada incrementa vitalidad, sentimiento de claridad, fuerza 
y poder ( $p$. 78). Qué actor o bailarín no ha experimentado el hecho de que conforme los agujeros negros en su línea de acción desaparecen, se fortalece su presencia escénica, llegando a experimentar un sentimiento de claridad y de vitalidad creadora. Desde mi punto de vista, una acción que se realiza con alto grado de inconsciencia es como un agujero negro en la escena, por donde se desaparecen grandes cantidades de energía que nunca llegan a concretarse en elementos de intercambio con el espectador. Y por esos agujeros negros se va también la atención del espectador.

Cuantas veces vemos en los laboratorios de danza y teatro estudiantes frustrados, cansados de tanto intento o de los que se dice que "no sirven para esto". No se puede tener responsabilidad y mucho menos capacidad de modificar los propios patrones de comportamiento cuando en nuestra acción estamos disociados. Por lo tanto, es para mí la experiencia de "darse cuenta" la que permite esta la vitalidad escénica.

\section{Del efecto terapéutico de las prácticas artísticas escénicas}

Entonces, los procesos artísticos pueden tener efectos terapéuticos en el artista. Pero no es una terapia, al menos no completa y consciente, puesto que este efecto terapéutico no es el principal fin de un proceso creativo o puesta en escena. Aunque algunos proceso pudieran ser casi completos en cuanto a lo que se habla y se verbaliza de la experiencia individual, llegando a la liberación a través de un proceso bastante complejo de movimiento y verbo donde el bailarín reconoce algunos de sus argumentos vitales y libera resistencias. Sin embargo, el objetivo primordial es siempre estético, entorno a un tema o a un limitado sistema de relaciones, de manera que si a mitad de un proceso se decide que ya se ha obtenido lo que se buscaba para la puesta

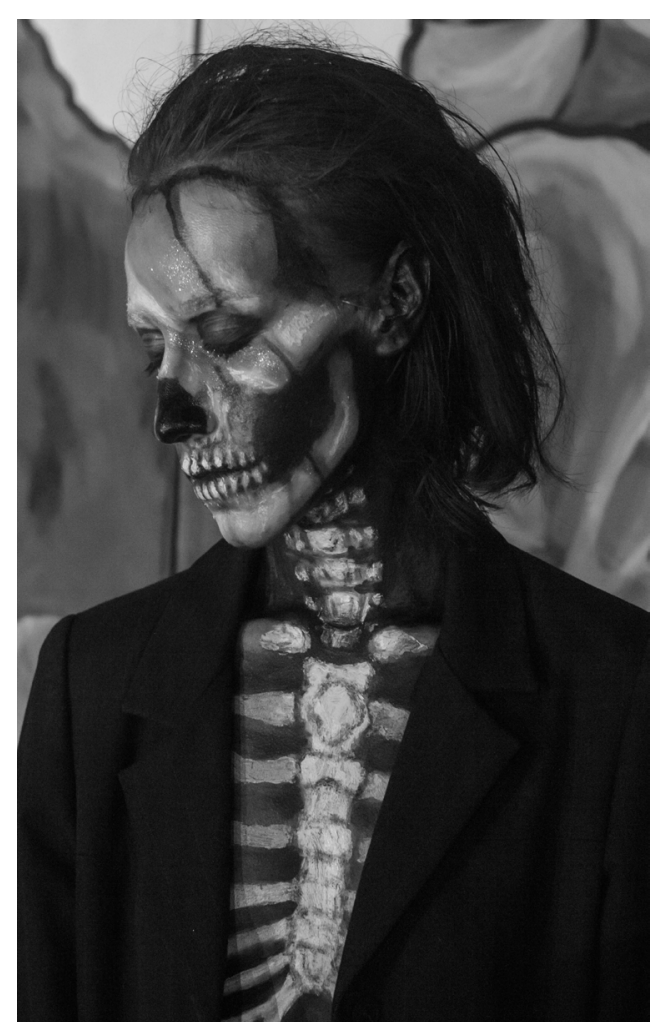

en escena, el proceso se detiene allí y aun cuando no haya sido completado (desde el punto de vista terapéutico). Es solamente por interés personal y capacidades individuales que la persona pudiera llegar a completarlo por su cuenta o de manera gradual en sucesivos procesos artísticos o personales.

Otras veces, la liberación puede ser inconsciente y no ser puesta nunca en relación con los argumentos vitales de la persona, la liberación está sucediendo, pero sin tener contacto con el origen, ello abre la posibilidad de volver al patrón que la generó. En el caso de algunos procesos artísticos o formativos donde se evita hacer contacto con lo personal, las liberaciones son más lentas, pero no menos profundas. Se evita la consciencia de lo que se hace en relación con la vida personal, y eso genera tensión, misma que es el principal material para la escena. Desde mi punto de vista, aun cuando estos artistas trabajan constantemente en su relajación corporal, el proceso suele ser más 
lento menos constante al no hacer contacto directo con el origen de la tensión.

\section{El "darse cuenta" en la confor- mación del estilo}

Las diferentes formas de gestionar las diversas zonas del "darse cuenta" resultan en varios estilos: podríamos identificar por ejemplo, tendencias a la sutileza, cuando hay una mayor atención a la vida interna del cuerpo, es decir, en lo que ocurre de bajo de la piel. Podría decirse que en esta predilección, por la vida interna, el artista se ocupa menos de los aspectos externos de su arte. Se puede decir que pone en juego los materiales de la escena (cuerpo, espacio, tiempo) siempre desde la perspectiva de su propia acción escénica.

Otra tendencia se presenta donde hay predilección por explorar las formas de contactar con el mundo externo desde una corporalidad que genera un mayor grado de tensión y contiene más la energía. Esta vertiente atiende en mayor medida a la forma en que se proyecta el movimiento en el espacio escénico y a la forma en que los cuerpos irradian su energía. Estos artistas transitan generalmente entre su consciencia de ser transformadores de la energía y su consciencia de ser receptores de estímulos externos.

A partir de estos matices y diferencias en las relaciones consigo mismo y con su entorno se van conformando los propios límites y características propias de un estilo. Mientras algunos artistas trabajan en profundidad con su propia historia de vida, otros se concentran en la inmediatez de sus acciones y otros tantos en situaciones ficticias. Algunas otras búsquedas más racionales e intelectuales parten de reglas muy específicas y con el objetivo explícito de reunir en los artistas habilidades que se traduzcan en eficiencia escénica. Otras más son organizadas principalmente a partir de leyes físicas y la puesta en relación de la energía creando estructuras de acciones visibles que después se asocian libremente con las creaciones mentales del artista, del director o del público. De esta manera, se llega a posibles interpretaciones y a la aparición de personajes en la escena.

No obstante las diferencias, actualmente está muy valorada la capacidad del artista para adquirir una mayor consciencia de la vitalidad creadora de su cuerpo. La comprensión de sus motivaciones. La percepción y clarificación de su intencionalidad. Un impulso hacia la acción y la transformación del espacio-tiempo que experimenta. Así como un "darse cuenta" de su afectación y la del otro. Por caminos distintos, diferentes modalidades y estilos del hacer escénico se ha buscado el equilibrio de las tres zonas de conciencia descritas anteriormente (mundo interno, mundo externo y creaciones mentales) resultando en prácticas híbridas como la del actor-bailarín, el bailarín-actor, el performer, etc.

\section{De la experiencia espacio-tem- poral y la movilización de la energía}

Generalmente los grupos de artistas o de estudiantes se conforman con personas que poseen diferentes sistemas de valores y por lo tanto, presentan diferencias entre sus mundos perceptuales, es decir, en la forma en que ven y sienten el mundo, pero con el paso de los años y la afirmación de una cultura grupal, se van capacitando para atender o ignorar ciertas cosas. Aunque pareciera que el objetivo primordial es la no alienación de la experiencia, encontrando un modo de relacionarse más consistente y real, vivo y por lo tanto orgánico.

Para Stevens (1998), el explicar, el interpretar y el justificar serían operaciones que se dan en el terreno de la fantasía, y te llevan a perder contacto con la experiencia en sí. El trabajo del artista escénico parece ser el de la acción consciente y 
viva, una acción que no es impulsada por una idea preconcebida, sino que nace de un "darse cuenta" que la acción sucede de por sí, y habla por sí misma.

Nuestra experiencia del espacio se construye de aspectos visuales, cinestésicos, táctiles y térmicos de la propia persona y a partir de allí se prolongan en mayor o menor medida en el espacio-tiempo escénico y teatral. El artista escénico poco a poco va conformando una sensación espacio-temporal bastante compleja que se construye a partir de una detallada sensación de sí mismo.

Cuando el artista moldea, mide, cimienta sus acciones y controla su flujo de energía, construye también un mundo posible en el cual desenvolverse. Cuanto más profundo es este "darse cuenta", más fuerte es su poder para externalizarse integrando aspectos más complejos de las formas a su alrededor, los gestos propios, fundiéndose y prolongándose con su entorno. Es a partir de este ponerse en acción de manera consciente que el artista se da cuenta del surgimiento de las relaciones espacio-temporales.

\section{Consideraciones finales: tra- bajando en el "darse cuenta"}

Como explicamos anteriormente el "darse cuenta", es decir, el proceso de construcción de la corporalidad consciente, moviliza siempre nuestras reservas de energía. Cada parte del cuerpo participa en la acción ya sea concordando o discrepando, desde lo individual y después en contacto con el colectivo. Entre más partes del cuerpo, aspectos psicológicos y extensiones del cuerpo o extensiones espacio-temporales son consideradas dentro de la acción, tanto más energía e información se acumula en el espacio que ocupa el artista, dilatando la acción, haciéndola visible y contundente. Las diferencias entre uno y otro artista dependen, desde esta perspectiva, de su forma de comportarse, del grado de consciencia con que sus ac- ciones se llevan a cabo, y el modo en que se focaliza su atención.

La acción de artista que se da cuenta de manera más o menos equilibrada en sus tres zonas de consciencia transita entre su mundo interno, se contacta con el mundo externo y también permite el juego y la creación mental. En el análisis minucioso de sus acciones se cuestionan sus argumentos vitales identificando estructuras de pensamiento y emociones. La escena es entonces, una danza de contacto, de contacto con el sí mismo y con el mundo a través de la movilización del cuerpo tanto a nivel físico como mental.

A partir del "darse cuenta", los cuerpos se comunican, juegan a moverse y ser movidos, exploran y clarifican sus impulsos. $\mathrm{Al}$ involucrarse de forma más consciente en la exploración de sus tres zonas de consciencia, el artista encara de forma crítica y no automatizada su presencia en la escena, al tiempo que se le presentan mayores opciones para poder decidir y vivenciar su acción. Y de la misma manera para poner sus acciones en relación con su entorno, con las demás personas.

Me pregunto ahora si las personas que tenemos a nuestro cargo la responsabilidad de coordinar espacios de enseñanza-aprendizaje - llámese asignaturas, talleres, laboratorios, etc. - podríamos explorar con mayor paciencia y dedicación estos procesos de concientización que empoderan al intérprete. Considero que muchas veces se subestima la sensibilidad, el disenso y el poder de decisión sobre la acción frente al logro de objetivos, la consecución con ciertos ideales de cuerpo o la devoción a un estilo.

Desde mi punto de vista, este contactar con sus tres zonas de consciencia permite desarrollar la capacidad de discernir su rango de influencia y campo de acción tanto en el proceso de creación escénica, como en la decisión sobre los aspectos de su corporalidad que se atenderán con mayor prioridad. Al mismo tiempo, asumir su posición en la dinámica social 
del grupo y en un contexto más amplio, puede ayudar a identificar con mayor claridad la forma en que acciona el colectivo al que pertenece en intercambio con los círculos sociales en los que se desenvuelven.

Fotografía: Alan Roberto Daniel Ortega

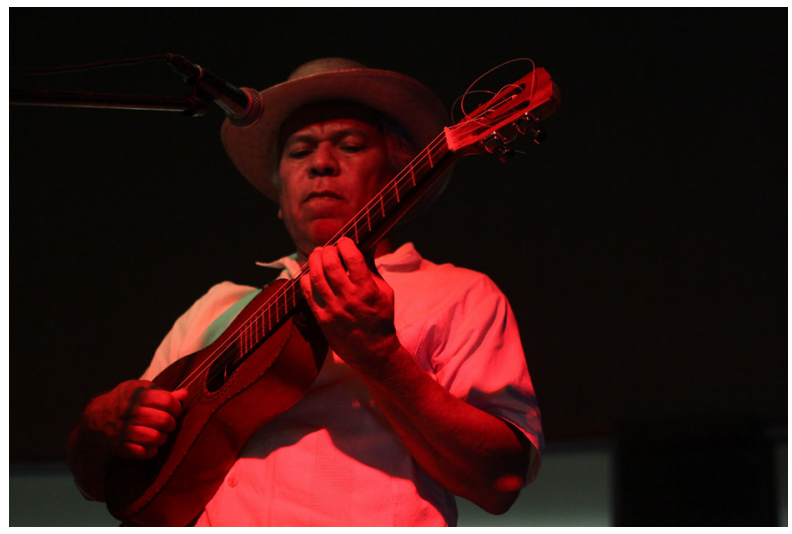

\section{Bibliografía}

Grinberg, J. (1981). El espacio y la conciencia. México: Trillas.

López, P. (2016). La capacidad de darse cuenta. Corporalidad consciente del actor-bailarín en la danza-teatro de Pina Bausch y el teatro que danza de Eugenio Barba. (Tesis de Maestría). Universidad de Sonora, Hermosillo.

Stevens, J. (1998). El darse cuenta. Santiago: Cuatro vientos.

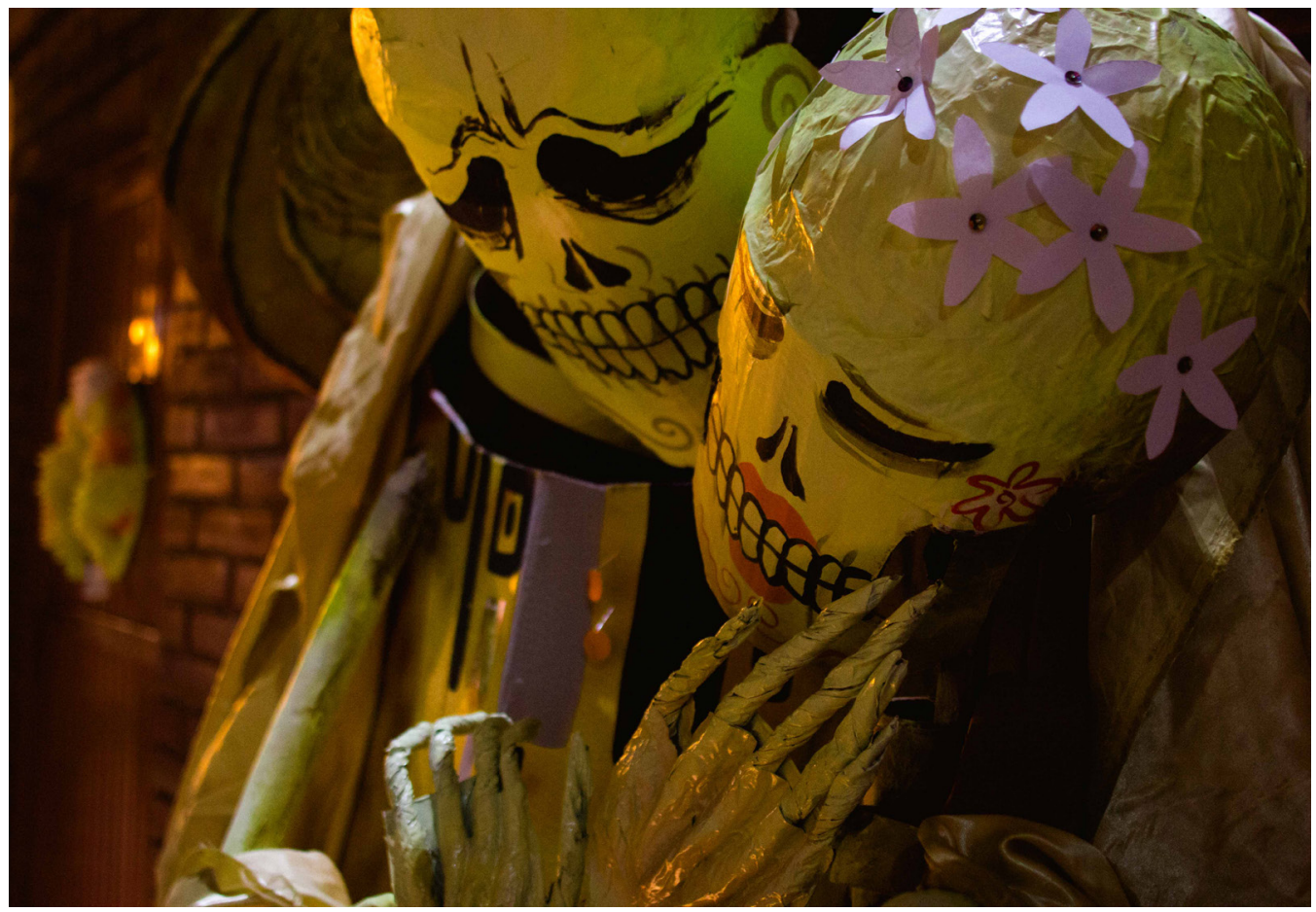

